\title{
Millimeter-Wave MMIC Passive HEMT Switches Using Traveling-Wave Concept
}

\author{
Kun-You Lin, Member, IEEE, Wen-Hua Tu, Ping-Yu Chen, Hong-Yeh Chang, Student Member, IEEE, \\ Huei Wang, Senior Member, IEEE, and Ruey-Beei Wu, Senior Member, IEEE
}

\begin{abstract}
This paper describes the design of millimeter-wave wide-band monolithic GaAs passive high electron-mobility transistor (HEMT) switches using the traveling-wave concept. This type of switch combined the off-state shunt transistors and series microstrip lines to form an artificial transmission line with $50-\Omega$ characteristic impedance. A 15-80-GHz single-pole double-throw (SPDT) switch in conjunction with quarter-wavelength impedance transformers demonstrates an insertion loss of less than $3.6 \mathrm{~dB}$ and an isolation of better than $25 \mathrm{~dB}$. Another type of wide-band switch was designed by using a series HEMT switch to replace the quarter-wavelength transformer, and the operating band can be extended to dc. With this scheme, dc-80-GHz single-pole single-throw (SPST) and dc-60-GHz SPDT switches are also developed with compact chip size. From dc to $80 \mathrm{GHz}$, the insertion loss and isolation of the SPST switch are better than 3 and $24 \mathrm{~dB}$, respectively. The SPDT switch has an insertion loss of better than $3 \mathrm{~dB}$ and an isolation of better than $25 \mathrm{~dB}$ from dc to $60 \mathrm{GHz}$. The analysis of circuit characteristics and design procedures are also included. It is concluded that the device periphery can be selected for the desired bandwidth, while the number of transistors is decided to achieve the isolation.
\end{abstract}

Index Terms-High electron-mobility transistor (HEMT), switch, traveling wave.

\section{INTRODUCTION}

$\mathbf{S}$ WITCHES ARE important components in communication systems, playing a role in controlling the RF signal flow. Recently, several switch circuits have been reported for millimeter-wave transceiver applications [1]-[12]. Switches utilizing a p-i-n diode have demonstrated good performance [1]; nevertheless, the processes of $\mathrm{p}$-i-n diodes and high electron-mobility transistors (HEMTs) are incompatible. The passive HEMT [or field-effect transistor (FET)] switches are still very popular since they are easy to fabricate with the HEMT monolithic-microwave integrated-circuit (MMIC) process and to integrate to other circuits on a single chip. Most passive

Manuscript received October 31, 2003; revised April 5, 2004. This work was supported in part by the National Science Council under Grant NSC 89-2213-E-002-178 and Grant NSC 89-2219-E-002-042, and by the Department of Education, R.O.C. under the Research Excellence Program ME 89-E-FA06-2-4.

K.-Y. Lin, H.-Y. Chang, H. Wang, and R.-B. Wu are with the Department of Electrical Engineering and Graduate Institute of Communication Engineering, National Taiwan University, Taipei 106, Taiwan, R.O.C. (e-mail: hueiwang@ew.ee.ntu.edu.tw).

W.-H. Tu was with the Department of Electrical Engineering and Graduate Institute of Communication Engineering, National Taiwan University, Taipei 106, Taiwan, R.O.C. He is now with the Electromagnetics and Microwave Laboratory, Texas A\&M University, College Station, TX 78363 USA.

P.-Y. Chen was with the Department of Electrical Engineering and Graduate Institute of Communication Engineering, National Taiwan University, Taipei 106, Taiwan, R.O.C. He is now with the Ministry of National Defense, R.O.C. Digital Object Identifier 10.1109/TMTT.2004.831574
HEMT switches were resonant-type FET switches [2], [3] with the isolation performance lower than $30 \mathrm{~dB}$. There were some other approaches for passive HEMT switches to obtain good isolation at the cost of huge chip area, such as high-isolation $Q$-band HEMT switches reported in [4], utilized two-stage unterminated quarter-wavelength shunt design to achieve up to 50-dB isolation, and a switching low-noise amplifier (LNA) using Lange couplers [5]. A new method utilizing impedance transformation to compensate the drain-to-source capacitance effect for the off-state passive HEMT switches performed better than 30-dB isolation [6]. Although these switches demonstrated good performance in the millimeter-wave frequency range, they are narrow-band designs. Wide-band switches using the traveling-wave concept were reported. 20-40- and dc-40-GHz traveling-wave switches using a MESFET were demonstrated [7]. An HEMT diode switch has broad-band characteristics [8], but it requires some capacitors for dc biasing and blocking. A dc-60-GHz heterojunction field-effect transistor (HJFET) MMIC switch [9] was reported with reasonable isolation performance, but it required a special process/layout for ohmic electrode-sharing technology (OEST) in the HEMT devices. Another dc-110-GHz MMIC traveling-wave switch [10] was reported with broad-band characteristics, but it also required a special structure of FET.

In this paper, the wide-band MMIC switches using the traveling-wave concept are demonstrated. The design method and design parameters of the traveling-wave passive HEMT switches are also discussed by using the simplified models of the passive HEMT. These MMIC switches are fabricated using a regular GaAs-based HEMT MMIC process without any special process/layout technology. A $15-80-\mathrm{GHz}$ single-pole double-throw (SPDT) switch reported in [12] has an insertion loss of less than $3.6 \mathrm{~dB}$ and an isolation of better than $25 \mathrm{~dB}$. DC-80-GHz single-pole single-throw (SPST) and dc-60-GHz SPDT switches are also presented in this paper. From dc to $80 \mathrm{GHz}$, the insertion loss and isolation of the SPST switch are better than 3 and $24 \mathrm{~dB}$, respectively. The SPDT switch has an insertion loss of better than $3 \mathrm{~dB}$ and an isolation of better than $25 \mathrm{~dB}$ from dc to $60 \mathrm{GHz}$. The bandwidths of these switches are comparable to the previously reported passive FET switches using a special layout/process [9], [10].

\section{Device Characteristics AND MMIC Process}

The MMIC switches were fabricated by a TRW high-linearity AlGaAs-InGaAs-GaAs pseudomorphic high electron-mobility transistor (pHEMT) MMIC process. The $15-80-\mathrm{GHz}$ SPDT switch was designed using a 0.1- $\mu \mathrm{m}$ HEMT process, while the dc-80-GHz SPST and dc-60-GHz SPDT switches were 


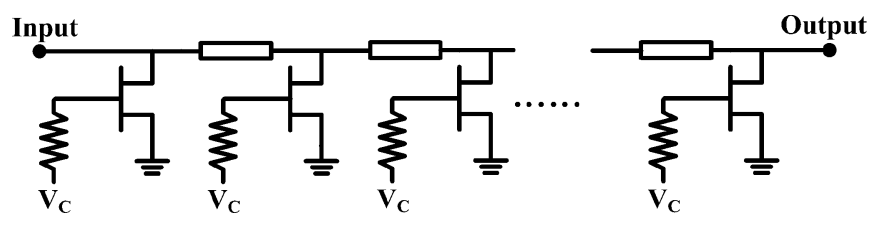

Fig. 1. Schematic of an SPST traveling-wave switch.

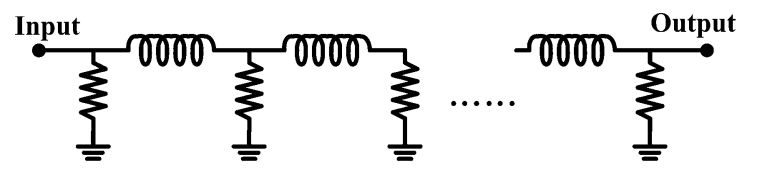

(a)

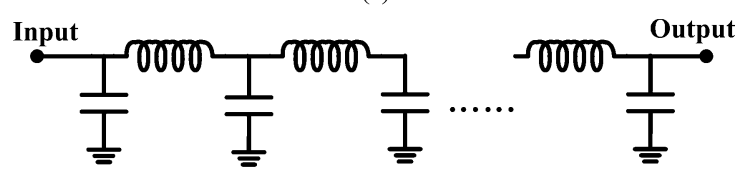

(b)

Fig. 2. Simplified schematic of the SPST switch with: (a) on- and (b) off-state HEMTs.

designed using a $0.15-\mu \mathrm{m}$ HEMT process. The HEMT device in a $0.1-\mu \mathrm{m}$ process has a typical unit current gain cutoff frequency $\left(f_{T}\right)$ of higher than $100 \mathrm{GHz}$ and maximum oscillation frequency $\left(f_{\max }\right)$ of greater than $250 \mathrm{GHz}$ at $2-\mathrm{V}$ drain bias, with a peak dc transconductance $\left(G_{m}\right)$ of $600 \mathrm{mS} / \mathrm{mm}$. The gate-drain breakdown voltage is $6 \mathrm{~V}$, and the drain current at peak $G_{m}\left(I_{d s p k}\right)$ at a $2-\mathrm{V}$ drain-source voltage is $600 \mathrm{~mA} / \mathrm{mm}$. The small-signal model is obtained by fitting measured device $S$-parameters to $50 \mathrm{GHz}$. The device characteristics and small-signal model of the $0.15-\mu \mathrm{m}$ process have been summarized in [6]. Other passive components include thin-film resistors, metal-insulator-metal (MIM) capacitors, spiral inductors, and air bridges. The wafer is thinned to 4 mil for the gold plating of the backside and reactive ion etching via-holes are used for $\mathrm{dc}$ grounding.

\section{Design AND ANalysis of SPST SwITCh Using TRAVELING-WAVE CONCEPT}

Millimeter-wave passive FET switches using the traveling-wave concept have been reported, and have demonstrated bandwidths of 20-40 and dc-40 GHz [7]. Fig. 1 shows the schematic of an SPST traveling-wave switch. The drain terminals are connected to the transmission lines and the source terminals are connected to ground. The gate terminals are biased using the large resistors. The transmission lines can be approximated by inductors at low frequency. The on-state HEMTs can be approximated by small resistors, and the off-state HEMTs can be approximated by small capacitors. The SPST traveling-wave switch shown in Fig. 1 can be simplified as Fig. 2(a) and (b), while the HEMTs are in on and off states, respectively.

When the HEMTs are in the off state, the SPST switch can be equivalent to a $50-\Omega$ artificial transmission line if the device periphery and transmission lines are properly selected and, thus, the input signal can easily flow to output. When the HEMTs are in the on state, the input impedance of the SPST switch is very low, and the input signal will be reflected.

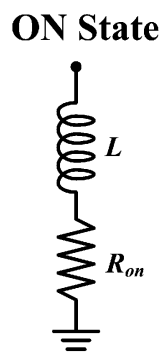

(a)

\section{OFF State}

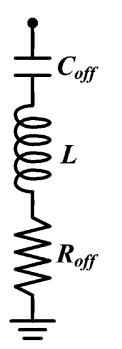

(b)
Fig. 3. Simplified models for: (a) on- and (b) off-state passive HEMTs.

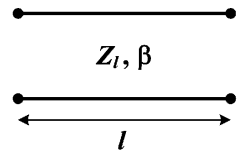

(a)

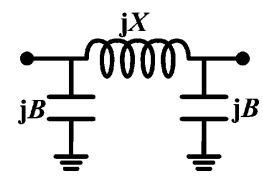

(b)

Fig. 4. (a) Ideal transmission line. (b) Lumped-element $\pi$ model for a short transmission line with an electric length smaller than $90^{\circ}$.

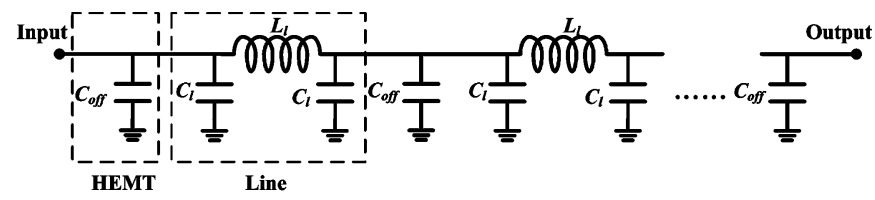

(a)

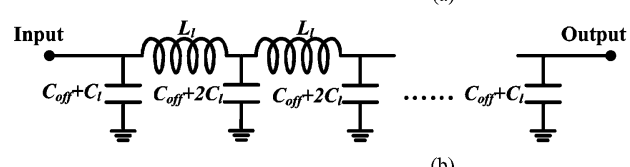

Fig. 5. Simplified schematic of the SPST switch with off-state transistors.

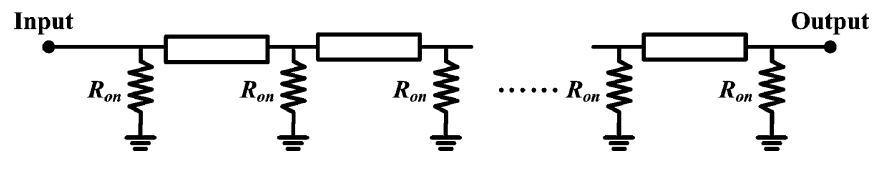

Fig. 6. Simplified schematic of the SPST switch with on-state transistors.

In order to analyze the traveling-wave switch performance, the simplified models of the passive HEMT, as shown in Fig. 3, are used here. The simplified models of the $0.15-\mu \mathrm{m}$ HEMT device have been verified in the millimeter-wave frequency range [6]. The parameters of the simplified models in the $0.1-\mu \mathrm{m}$ process related to the device gatewidth $W_{g}(\mu \mathrm{m})$ are as follows:

$$
\begin{aligned}
L & =0.1247 \times 10^{-12} \times W_{g}(\mathrm{H}) \\
R_{\text {on }} & =\frac{896}{W_{g}}(\Omega) \\
C_{\text {off }} & =0.4225 \times 10^{-15} \times W_{g}(\mathrm{~F}) \\
R_{\text {off }} & =\frac{120}{W_{g}}(\Omega) .
\end{aligned}
$$



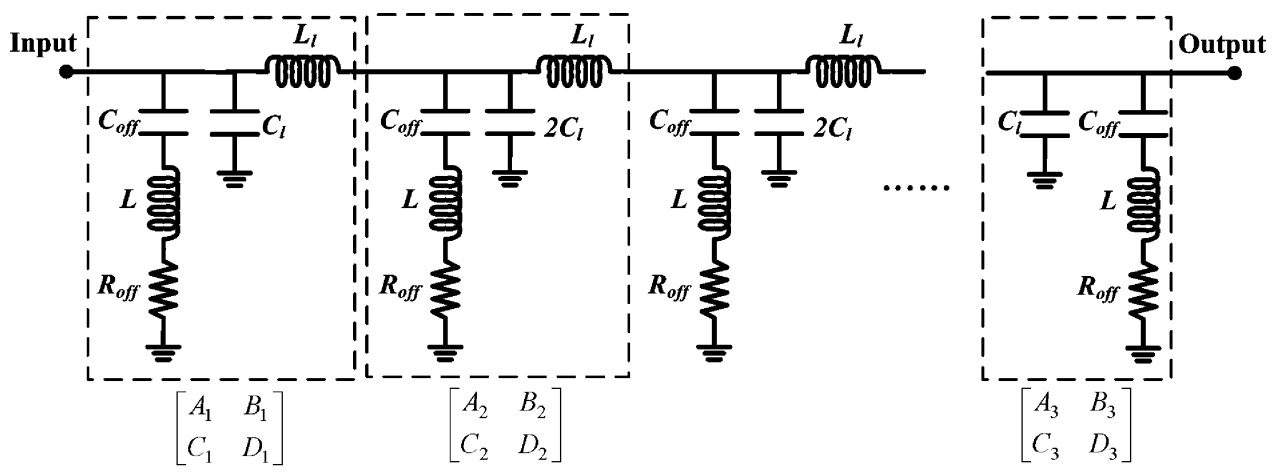

(a)
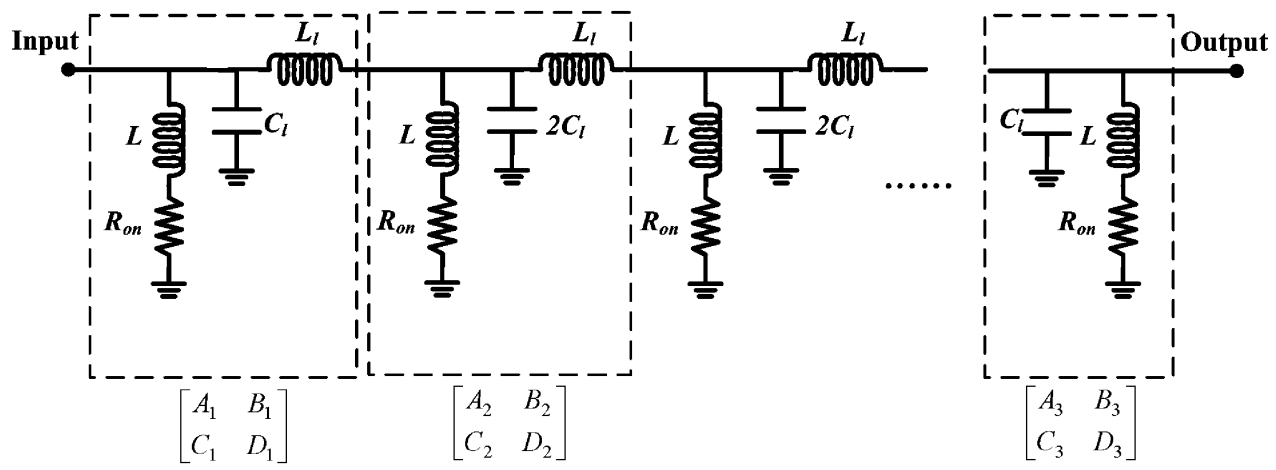

(b)

Fig. 7. Equivalent circuit of the SPST switch with: (a) off- and (b) on-state transistors.

When the electrical length of the transmission line is less than $90^{\circ}$, an ideal transmission line can be simplified as a lumpedelement $\pi$ model, as shown in Fig. 4. The parameters of the $\pi$ model are

$$
X_{\pi}=Z_{l} \sin (\beta l)
$$

and

$$
B_{\pi}=\frac{1}{Z_{l}} \frac{1-\cos (\beta l)}{\sin (\beta l)}
$$

where $Z_{l}$ is the characteristic impedance, $\beta$ is the propagation constant, and $l$ is the physical length of the transmission line.

In order to estimate the initial circuit parameters of the traveling-wave switch, the $\pi$ model is used to replace the transmission line, and off-state transistors are replaced by the capacitor $\left(C_{\text {off }}\right)$ of the simplified model. The SPST switch with off-state transistors, shown in Fig. 1, can be simplified as shown in Fig. 5(a). We can combine the shunt capacitors to simplify the circuit, shown in Fig. 5(b); this circuit can be taken as an artificial transmission line. The equivalent inductance and capacitance are

$$
L_{l}=\frac{Z_{l} \sin (\beta l)}{\omega}
$$

and

$$
C_{l}=\frac{1}{\omega Z_{l}} \frac{1-\cos (\beta l)}{\sin (\beta l)} .
$$

The total capacitance of the artificial transmission line is

$$
C_{t}=C_{\text {off }}+2 C_{l} \text {. }
$$

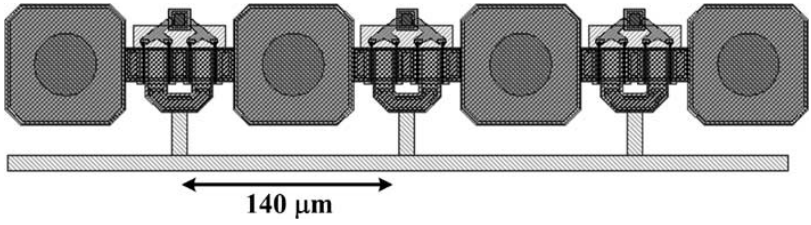

Fig. 8. Layout of the four-finger HEMTs and via-holes.

The first and last capacitors in Fig. 5(b) are not equal to $C_{t}$, but they are equal to $\left(C_{\text {off }}+C_{l}\right)$. This difference will be neglected while calculating the characteristic impedance of the artificial transmission line because $C_{l}$ is much smaller than $\left(C_{\text {off }}+C_{l}\right)$. The characteristic impedance of the artificial transmission line is

$$
Z_{0}=\sqrt{\frac{L_{l}}{C_{t}}}
$$

which can be calculated by equivalent inductance and total capacitance.

For the given characteristic impedance $\left(Z_{0}\right)$ of the artificial transmission line, the characteristic impedance of the transmission line is

$$
Z_{l}=\frac{Z_{0}^{2} \omega C_{\text {off }}+\sqrt{\left[Z_{0}^{2} \omega C_{\text {off }}\right]^{2}-8\left[Z_{0}^{2} \cos (\beta l)-Z_{0}^{2}\right]}}{2 \sin (\beta l)} .
$$

When the transistors are in the on state, the SPST switch, shown in Fig. 1, can be represented as shown in Fig. 6. This circuit can be treated as a high-loss transmission line. The input impedance of switch is very low and the input signal will be reflected.

In order to estimate the performance of the SPST traveling-wave switch, we use the simplified models to replace 


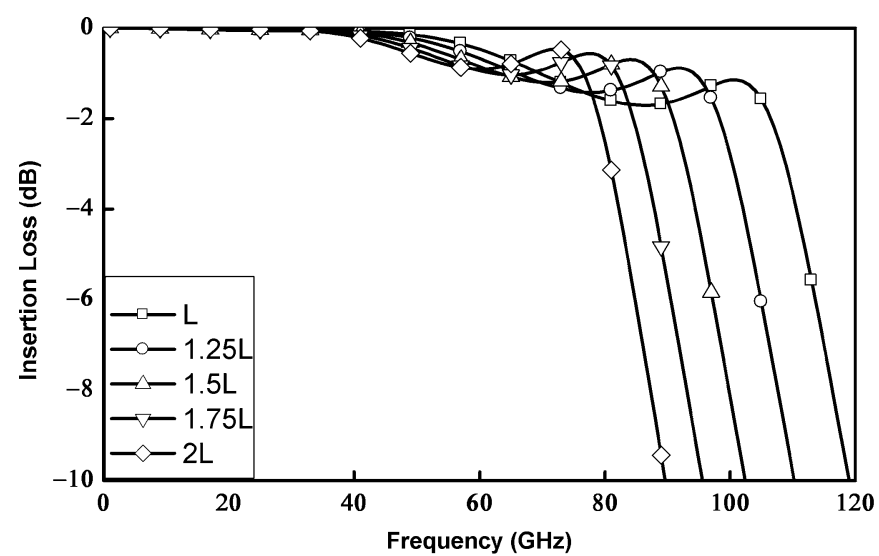

(a)

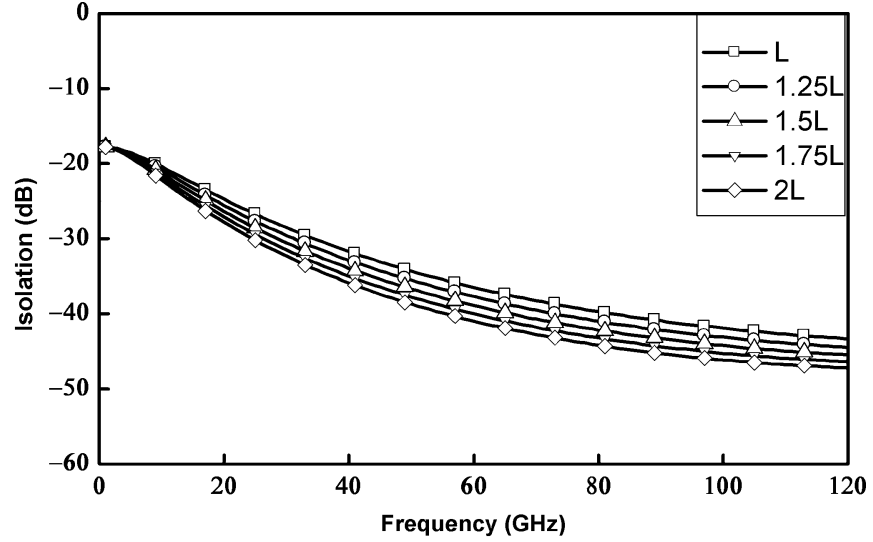

(b)

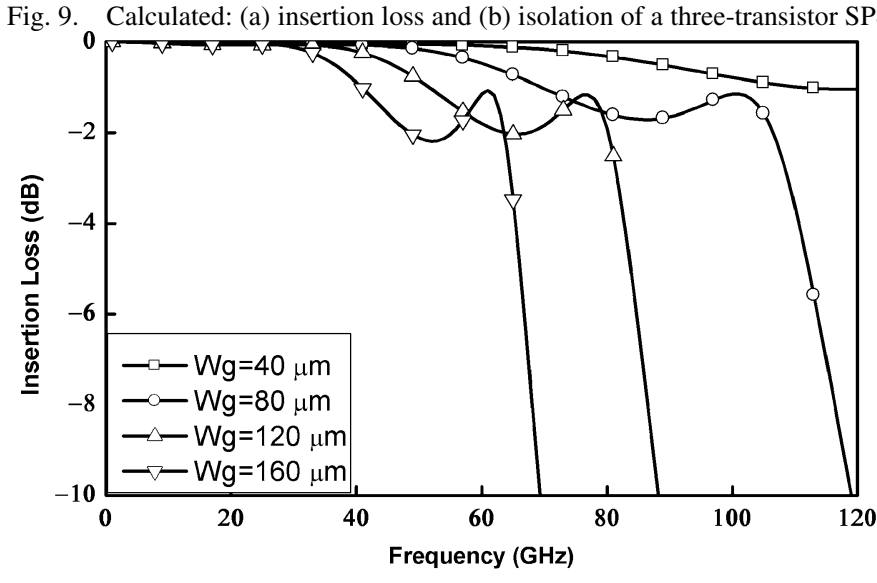

(a)

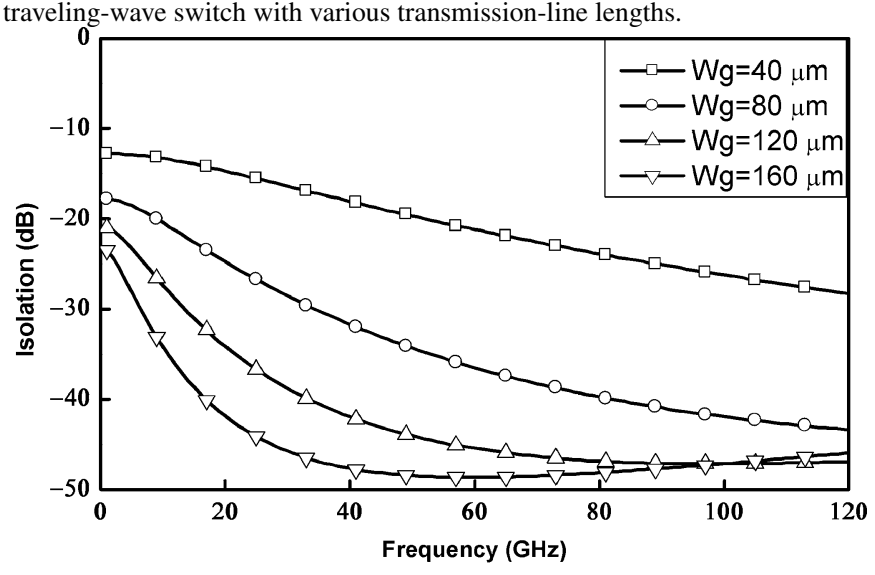

(b)

Fig. 10. Calculated: (a) insertion loss and (b) isolation of a three-transistor SPST traveling-wave switch with various device sizes.

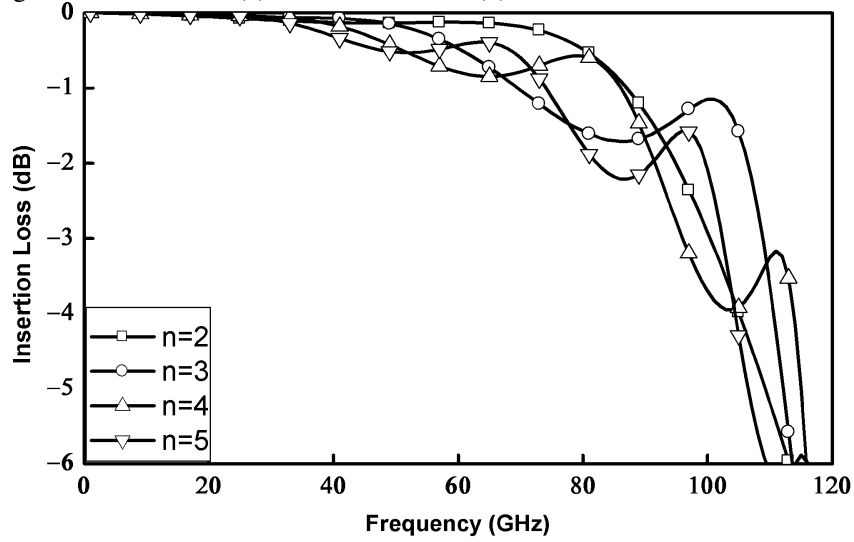

(a)

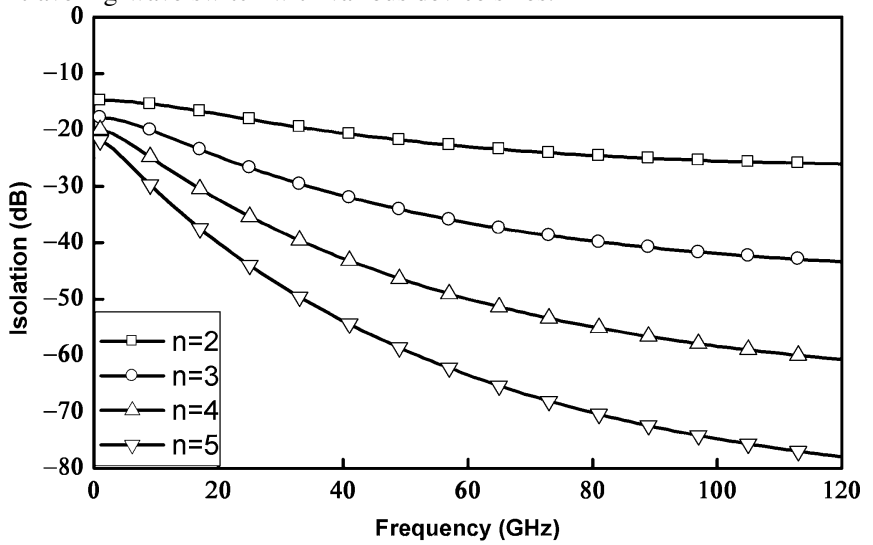

(b)

Fig. 11. Calculated: (a) insertion loss and (b) isolation of a three-transistor SPST traveling-wave switch with various number of transistors.

the transistors and lumped-element $\pi$ model to replace the transmission lines. The SPST switch can be represented as Fig. 7(a) and (b), respectively, while the transistors are in the off and on states.

The equivalent circuit of the SPST traveling-wave switch can be divided into three parts, which are shown in Fig. 7(a) and (b). The $A B C D$ matrix of the whole SPST switch can be represented as (9), where $n$ is number of transistors in the switch $(n \geqq 2)$. The $A B C D$ matrix of the SPST traveling-wave switch, as shown in Fig. 1, is

$$
\left[\begin{array}{ll}
A & B \\
C & D
\end{array}\right]=\left[\begin{array}{ll}
A_{1} & B_{1} \\
C_{1} & D_{1}
\end{array}\right]\left[\begin{array}{ll}
A_{2} & B_{2} \\
C_{2} & D_{2}
\end{array}\right]^{n-2}\left[\begin{array}{cc}
A_{3} & B_{3} \\
C_{3} & D_{3}
\end{array}\right]
$$

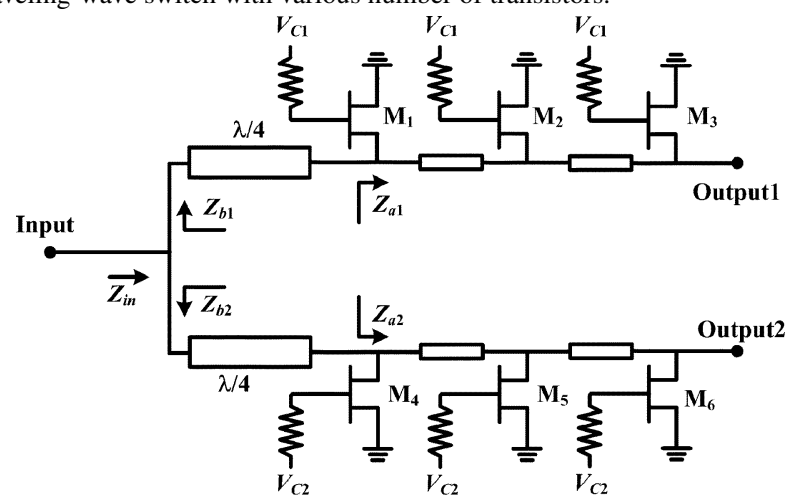

Fig. 12. Schematic of the SPDT traveling-wave switch in conjunction with a quarter-wavelength impedance transformer. 


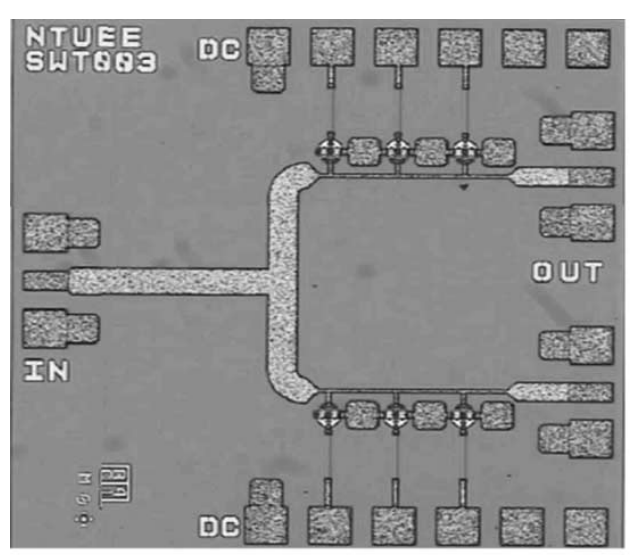

(a)

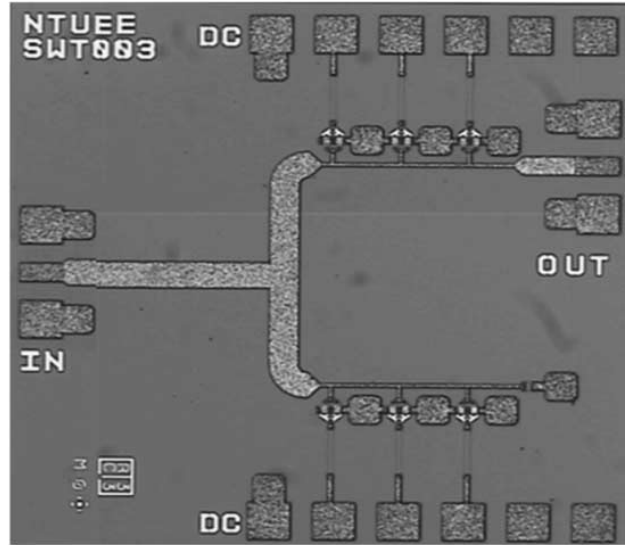

(b)

Fig. 13. Chip photograph of the SPDT traveling-wave switch: (a) without and (b) with a $50-\Omega$ termination at the second output port.

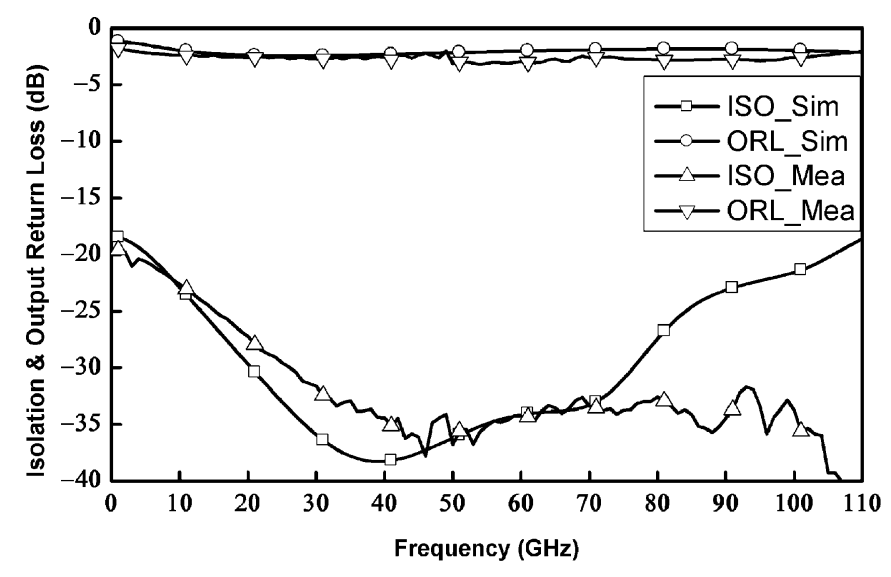

(a)

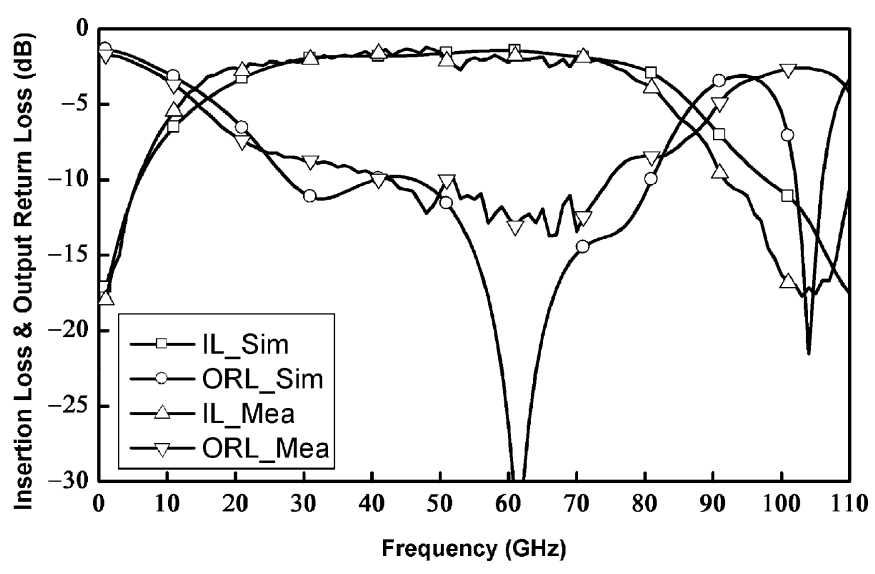

(b)

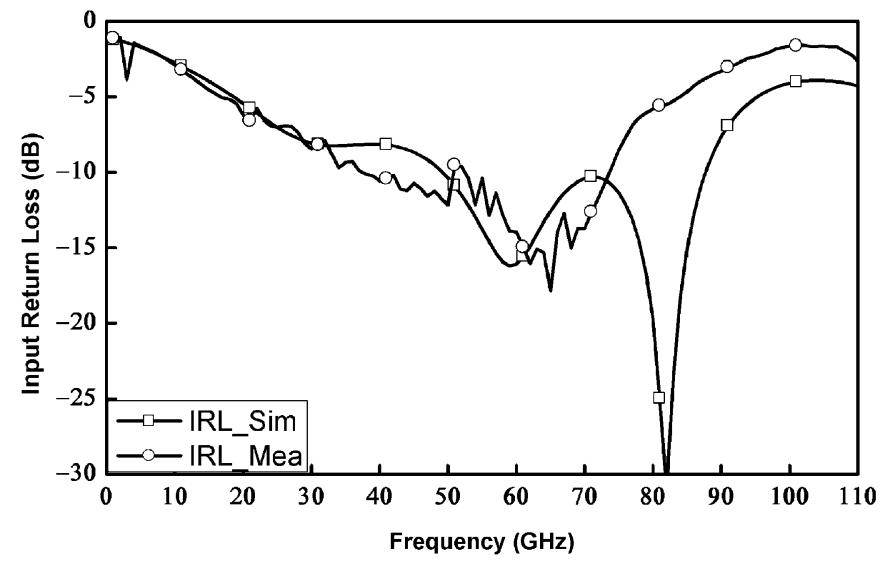

(c)

Fig. 14. Simulated and measured results of: (a) output return loss and isolation of the off state, (b) output return loss and insertion loss of the on state, and (c) input return loss from 1 to $110 \mathrm{GHz}$ for the SPDT traveling-wave switch.

where

and

$$
\begin{aligned}
& {\left[\begin{array}{ll}
A_{1} & B_{1} \\
C_{1} & D_{1}
\end{array}\right]=\left[\begin{array}{cc}
1 & Z_{1} \\
Y_{1} & Y_{1} Z_{1}+1
\end{array}\right]} \\
& {\left[\begin{array}{ll}
A_{2} & B_{2} \\
C_{2} & D_{2}
\end{array}\right]=\left[\begin{array}{cc}
1 & Z_{1} \\
Y_{2} & Y_{2} Z_{1}+1
\end{array}\right]}
\end{aligned}
$$

$$
\left[\begin{array}{ll}
A_{3} & B_{3} \\
C_{3} & D_{3}
\end{array}\right]=\left[\begin{array}{cc}
1 & 0 \\
Y_{1} & 1
\end{array}\right]
$$

When the transistors are in the off state,

$$
\begin{aligned}
& Z_{1}=j \omega L_{l} \\
& Y_{1}=\frac{1}{\frac{1}{j \omega C_{\text {off }}}+R_{\text {off }}+j \omega L}+j \omega C_{l} \\
& Y_{2}=\frac{1}{\frac{1}{j \omega C_{\text {off }}}+R_{\text {off }}+j \omega L}+j 2 \omega C_{l}
\end{aligned}
$$




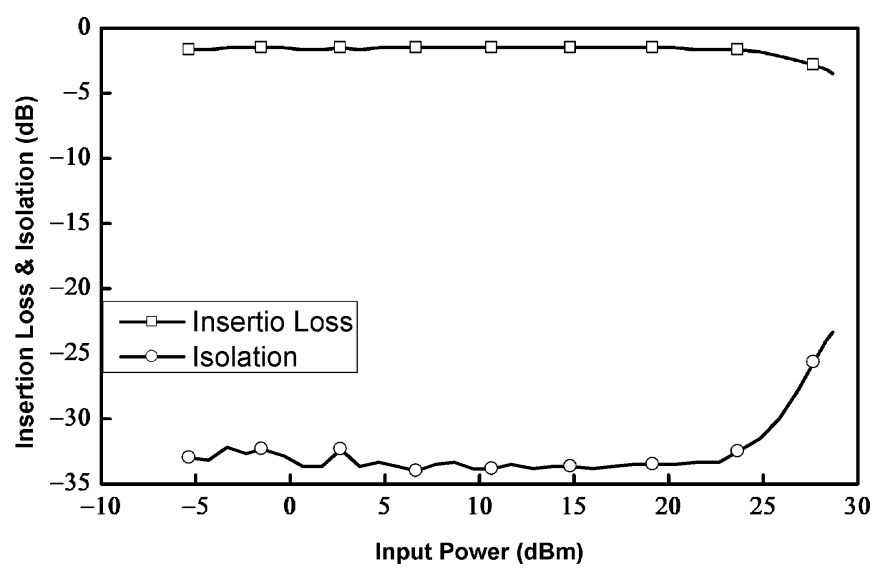

Fig. 15. Measured insertion loss and isolation versus input power at $35 \mathrm{GHz}$ of the SPDT switch.

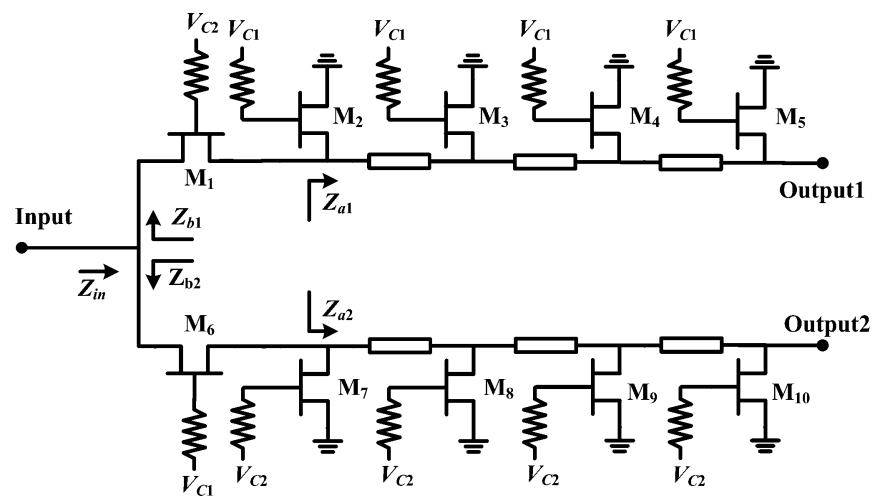

Fig. 16. Complete schematic of an SPDT traveling-wave switch using the series HEMT switches $\left(M_{1}\right.$ and $\left.M_{6}\right)$.

and when the transistors are in the on state,

$$
\begin{aligned}
& Z_{1}=j \omega L_{l} \\
& Y_{1}=\frac{1}{R_{\mathrm{on}}+j \omega L}+j \omega C_{l} \\
& Y_{2}=\frac{1}{R_{\mathrm{on}}+j \omega L}+j 2 \omega C_{l} .
\end{aligned}
$$

The $A B C D$ matrix of the complete switch can be easily calculated by (9)-(14), and the insertion loss and isolation of the SPST switch can be calculated from the parameters of the $A B C D$ matrix. By using these equations, the design parameters of a traveling-wave switch include the length of the transmission line $(l)$, device size $\left(W_{g}\right)$, and number of transistors $(n)$, which are discussed below.

\section{A. Length of the Transmission Line (l)}

The length of the transmission line is limited by the via-hole size, which is $80 \mu \mathrm{m}$ in this GaAs HEMT process. The layout of the four-finger HEMTs and via-holes is shown in Fig. 8, and the minimum length of the transmission line is $140 \mu \mathrm{m}$. An SPST traveling-wave switch with three transistors $(n=3)$ and a common device size of $80 \mu \mathrm{m}\left(W_{g}=80\right)$ is used as an example. Fig. 9 shows the insertion loss and isolation of the SPST switch with various lengths of the lines, where $L$ is the minimum physical length of the layout $(140 \mu \mathrm{m})$. As can be observed, the switch with the longer transmission line has a narrower bandwidth. Therefore, the minimum length of the transmission line is selected for the traveling-wave switch design.

\section{B. Device Size $\left(W_{g}\right)$}

The calculated insertion loss and isolation of an SPST switch with various device sizes are shown in Fig. 10. This switch has three transistors $(n=3)$, and the minimum length of the transmission line is used to calculate the switch performance. The device sizes of Fig. 10 are 40, 80, 120, and $160 \mu \mathrm{m}$. The line impedances used in the switches with 40-, 80-, 120-, and 160- $\mu \mathrm{m}$ transistors are $72.99,98,126.37$, and $156.84 \Omega$, respectively. The switch using a larger transistor has better isolation performance due to the smaller on-state resistor and poor insertion loss due to the larger off-state capacitor.

\section{Number of Transistors $(n)$}

Another design parameter is the number of transistors. The calculated insertion loss and isolation of an SPST switch with various numbers of the transistors are shown in Fig. 11. The device size of the SPST traveling-wave switch is $80 \mu \mathrm{m}\left(W_{g}=\right.$ $80)$ and the minimum length of the transmission line $(l=140)$ is used to calculate the line impedance and switch performance. The switch with more transistors has better isolation, but does not affect the insertion loss significantly.

\section{MMIC SWITCHES}

There are two methods to implement an SPDT traveling-wave switch; one is to use the quarter-wavelength transformers, and another is to use the series switches. The switch utilizing the quarter-wavelength transformers has a bandpass characteristic, and the SPDT switch utilizing the series switch has a low-pass characteristic. Both types of MMIC switches were implemented and are presented as follows.

\section{A. $15-80-G H z$ SPDT Switch}

This wide-band SPDT switch was fabricated by the TRW 0.1- $\mu \mathrm{m}$ GaAs pHEMT MMIC process. According to Fig. 10, the four-finger $80-\mu \mathrm{m}$ HEMT device was selected for the switch design due to the bandwidth of the insertion loss. To achieve the isolation of better than $20 \mathrm{~dB}$, the switch with three transistors was chosen (Fig. 11). Fig. 12 shows the complete schematic of the SPDT traveling-wave switch. Two identical SPST traveling-wave switch cells and two 50- $\Omega$ impedance transformers are used to form an SPDT switch. Since the input impedance $Z_{a 1}$ is not pure real impedance while $V_{C 1}$ is $0.3 \mathrm{~V}$, the length of the impedance transformer is shorter than $\lambda / 4$ of the center frequency for the switch. Each SPST switch has three transistors, and the gate terminals of the transistors are biased through large resistors (1.2 k $\Omega$ ). Fig. 13(a) shows the chip photograph, and the chip size is $1.5 \times 1.5 \mathrm{~mm}^{2}$. For on-wafer testing consideration, since we cannot place two ground-signal-ground (GSG) probes at the same side of the chip, a test circuit, which has a $50-\Omega$ 

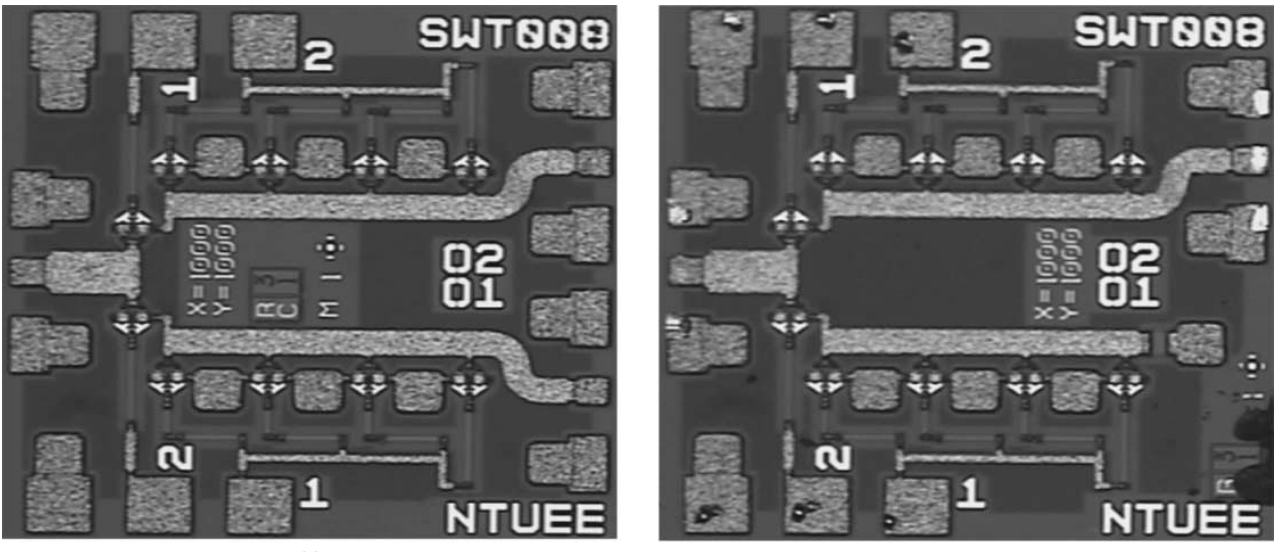

(a)

(b)

Fig. 17. Photograph of the dc-60-GHz SPDT traveling-wave switch: (a) without and (b) with a 50- $\Omega$ termination at the second output port.

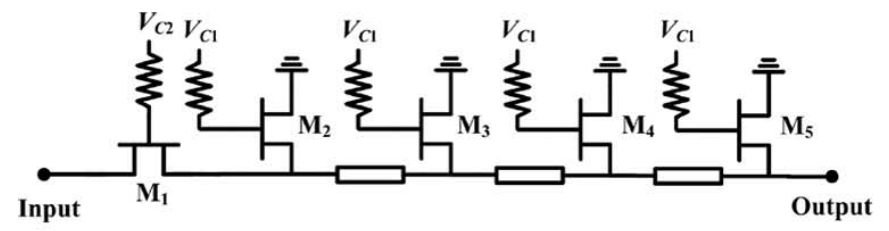

(a)

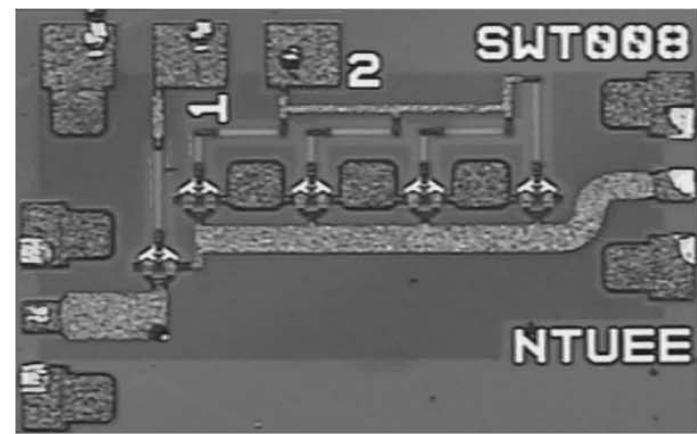

(b)

Fig. 18. (a) Schematic and (b) photograph of the dc-60 GHz SPST traveling-wave switch.

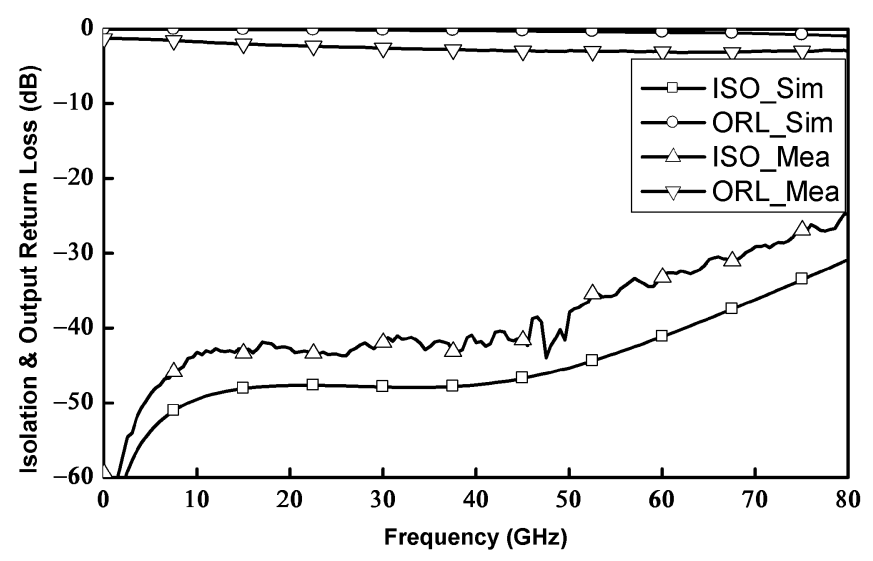

(a)

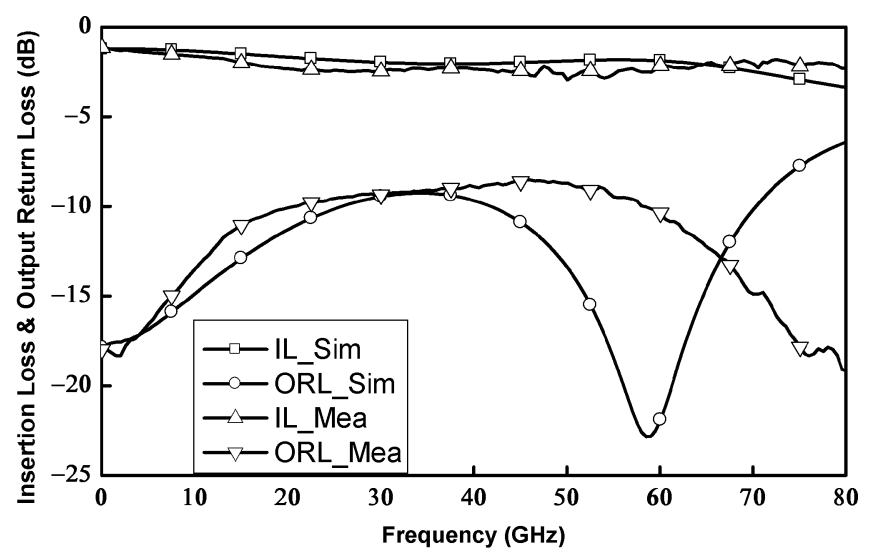

(b)

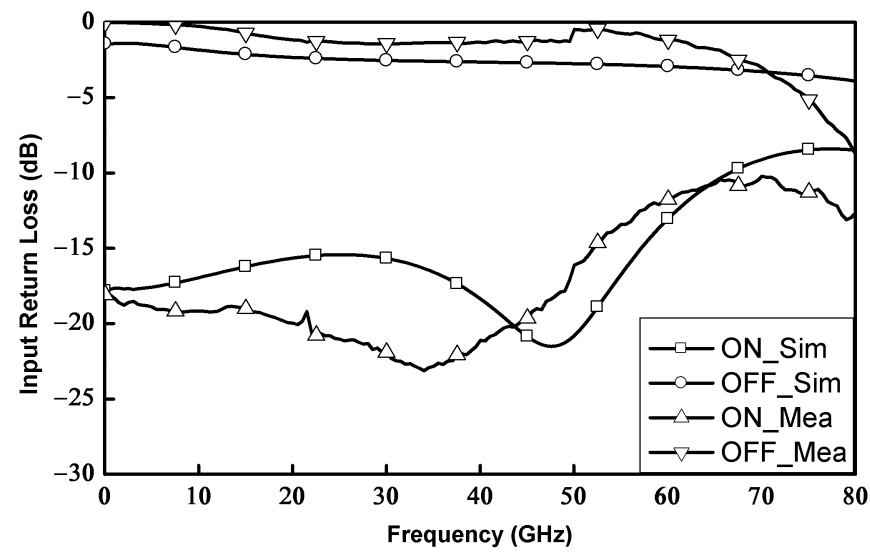

(c)

Fig. 19. Simulated and measured results of: (a) output return loss and isolation of the off state, (b) output return loss and insertion loss of the on state, and (c) input return loss from $45 \mathrm{MHz}$ to $80 \mathrm{GHz}$ for the SPST traveling-wave switch. 


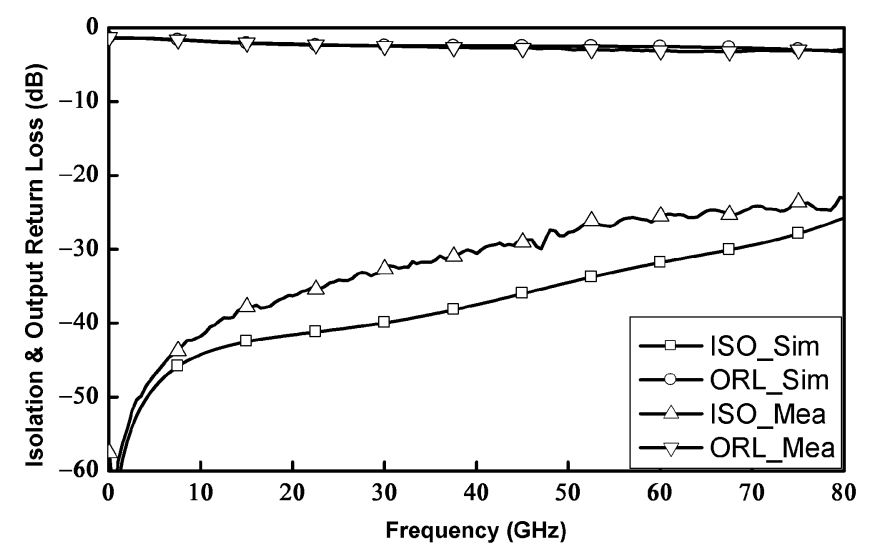

(a)

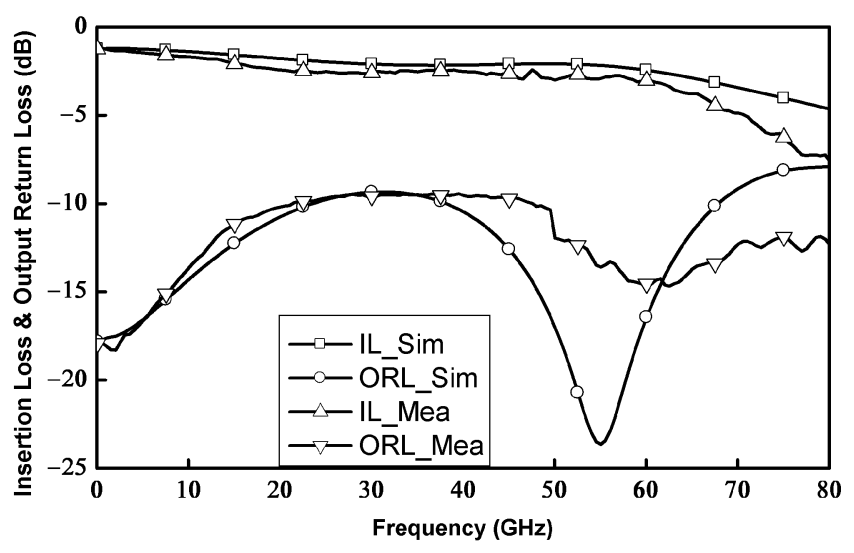

(b)

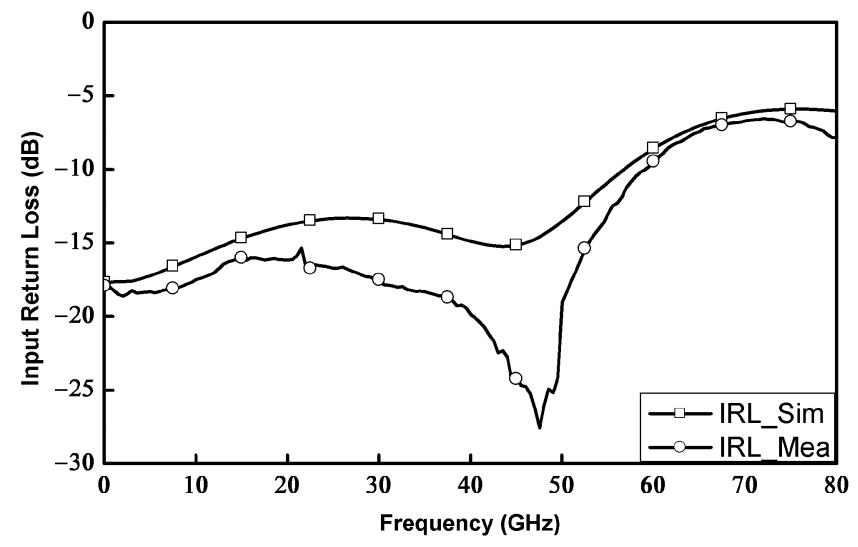

(c)

Fig. 20. Simulated and measured results of: (a) output return loss and isolation of the off state, (b) output return loss and insertion loss of the on state, and (c) input return loss from $45 \mathrm{MHz}$ to $80 \mathrm{GHz}$ for the SPST traveling-wave switch.

termination at the second output port, was fabricated, and the chip photograph of the test circuit is shown in Fig. 13(b).

Fig. 14(a) shows the simulated and measured output return loss and isolation of the off state, while Fig. 14(b)-(c) presents the simulated and measured output return and insertion losses of the on state and input return loss from 1 to $110 \mathrm{GHz}$. The insertion loss is less than $3.6 \mathrm{~dB}$, and the isolation is better than $25 \mathrm{~dB}$ from 15 to $80 \mathrm{GHz}$. The input return loss and on-state output return loss are better than $10 \mathrm{~dB}$ near the center frequency, and the return losses are 5-10 dB in the band edges. The power performance of this switch was also measured at $35 \mathrm{GHz}$. Fig. 15 shows measured insertion loss and isolation versus input power. The measured insertion loss and isolation start to degrade while the input power is $23 \mathrm{dBm}$. The $1-\mathrm{dB}$ compression point of the measured insertion loss is at $27-\mathrm{dBm}$ input power while the isolation degrades to approximately $25 \mathrm{~dB}$.

\section{B. DC-60-GHz SPST and SPDT Switches}

Fig. 16 shows the complete schematic of an SPDT traveling-wave switch employing the series switch. The on- and off-state series HEMT switches can be considered as a small resistor and a small capacitor. Due to the small capacitor of the off state, the series switch provide good isolation in the low-frequency range, and the operating band can be extended to dc. The insertion loss frequency response of this switch is similar to that of a low-pass filter, and the switches employing

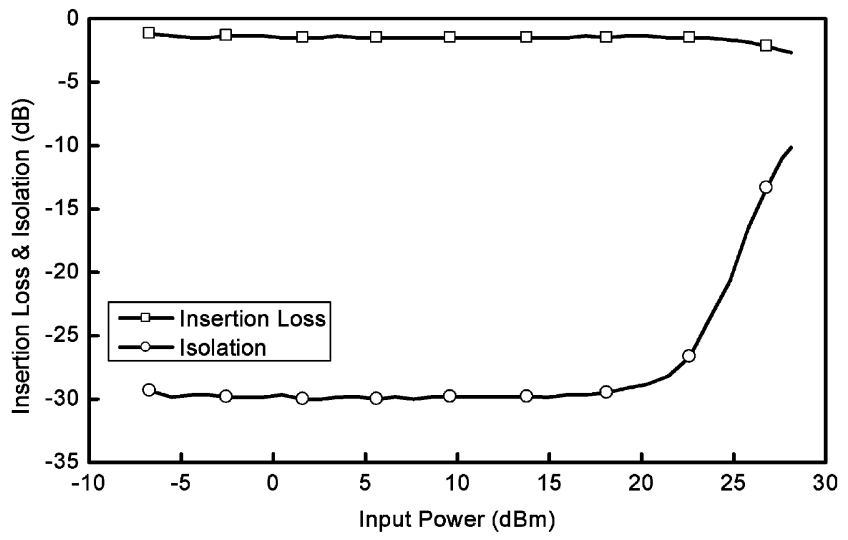

Fig. 21. Measured insertion loss and isolation versus input power at $35 \mathrm{GHz}$ of the dc-60-GHz SPDT switch.

the quarter-wavelength impedance transformers have bandpass characteristics.

This switch was designed using the $0.15-\mu \mathrm{m}$ GaAs HEMT MMIC process. Four-finger $60-\mu \mathrm{m}$ transistors were used in this switch design. Four transistors were used to compose a traveling-wave switch, and a single transistor was used as a series switch (Fig. 16). The drain terminals of the series transistors are connected to the input. The gate terminals of the transistors are biased through $1500-\Omega$ resistors. The chip photograph is shown in Fig. 17(a), and the chip size is $1 \mathrm{~mm} \times 1 \mathrm{~mm}$. In order to 
TABLE I

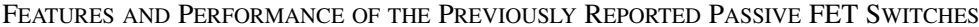

\begin{tabular}{|c|c|c|c|c|c|c|c|}
\hline Author & Device & Approach & $\mathrm{I} / \mathrm{O}$ & $\begin{array}{l}\text { Freq. Range } \\
(\mathrm{GHz})\end{array}$ & \begin{tabular}{|c|}
$\begin{array}{c}\text { Insertion Loss } \\
(\mathrm{dB})\end{array}$ \\
\end{tabular} & $\begin{array}{l}\text { Isolation } \\
\text { (dB) }\end{array}$ & $\begin{array}{c}\text { Chip Size } \\
\left(\mathrm{mm}^{2}\right)\end{array}$ \\
\hline $\begin{array}{l}\text { G. L. Lan et al., } \\
{[2]}\end{array}$ & HEMT & Resonant, series & SPDT & $54 \sim 64$ & $<3.2$ & $>23$ & $\begin{array}{l}0.8 X \\
2.45\end{array}$ \\
\hline $\begin{array}{l}\text { H. Takasu et } \\
\quad \text { al., [3] }\end{array}$ & HEMT & Resonant, series & SPST & 94 & 1.6 & 22.5 & - \\
\hline $\begin{array}{l}\text { D. L. Ingram et } \\
\text { al., [4] }\end{array}$ & HEMT & $\lambda / 4$, shunt & SPDT & $42 \sim 46$ & $<1.6$ & $35 \sim 50$ & $5 \times 2$ \\
\hline $\begin{array}{l}\text { D. C. W. Lo et } \\
\text { al., [5] }\end{array}$ & HEMT & $\begin{array}{c}\text { Phase cancellation using } \\
\text { Lange couplers }\end{array}$ & SPDT & $92 \sim 95$ & - & $28 \sim 38$ & $\begin{array}{l}1.3 \mathrm{X} \\
2.2^{*}\end{array}$ \\
\hline $\begin{array}{l}\text { D. C. W. Lo et } \\
\text { al., [5] }\end{array}$ & HEMT & $\begin{array}{c}\text { Phase cancellation using } \\
\text { Lange couplers }\end{array}$ & SPDT & $33 \sim 38$ & - & $18 \sim 28$ & $\begin{array}{l}1.8 \mathrm{X} \\
2.4^{*}\end{array}$ \\
\hline $\begin{array}{l}\text { K. Y. Lin et al., } \\
{[6]}\end{array}$ & HEMT & $\begin{array}{l}\text { Impedance transformation } \\
\text { network, shunt }\end{array}$ & SPDT & $38 \sim 43$ & $<2$ & $>30$ & $2 \times 1$ \\
\hline $\begin{array}{l}\text { K. Y. Lin et al., } \\
{[6]}\end{array}$ & HEMT & $\begin{array}{l}\text { Impedance transformation } \\
\text { network, shunt }\end{array}$ & SPDT & $53 \sim 61$ & $<4$ & $>30$ & $2 \times 1$ \\
\hline $\begin{array}{l}\text { M. J. Schindler } \\
\text { et al., [7] }\end{array}$ & MESFET & $\begin{array}{c}\text { Traveling-wave concept, } \\
\text { shunt }\end{array}$ & SPDT & $20 \sim 40$ & $<2$ & $>23$ & $\begin{array}{c}1.25 \mathrm{X} \\
1.25\end{array}$ \\
\hline $\begin{array}{l}\text { M. J. Schindler } \\
\text { et al., [7] }\end{array}$ & MESFET & $\begin{array}{c}\text { Traveling-wave concept, } \\
\text { shunt }\end{array}$ & SPDT & $\mathrm{DC} \sim 40$ & $<3$ & $>23$ & $\begin{array}{c}0.84 \mathrm{X} \\
1.27\end{array}$ \\
\hline $\begin{array}{c}\text { T. Shimura et } \\
a l .,[8]\end{array}$ & $\begin{array}{c}\text { HEMT } \\
\text { Diode }\end{array}$ & $\begin{array}{c}\text { Traveling-wave concept, } \\
\text { shunt }\end{array}$ & SPDT & $23 \sim 78$ & $<4$ & $>25$ & $\begin{array}{c}2.65 \mathrm{X} \\
1.33\end{array}$ \\
\hline $\begin{array}{l}\text { H. Mizutani et } \\
\text { al., [9] }\end{array}$ & HJFET & $\begin{array}{l}\text { Ohmic electrode-sharing } \\
\text { technology, series shunt }\end{array}$ & SPDT & $\mathrm{DC} \sim 40$ & $<3.5$ & $>25.5$ & $\begin{array}{c}0.86 \mathrm{X} \\
0.64\end{array}$ \\
\hline $\begin{array}{l}\text { H. Mizutani et } \\
\text { al., [9] }\end{array}$ & HJFET & $\begin{array}{l}\text { Ohmic electrode-sharing } \\
\text { technology, series shunt }\end{array}$ & SPST & $\mathrm{DC} \sim 60$ & $<1.64$ & $>20.6$ & $\begin{array}{c}0.52 \mathrm{X} \\
0.63\end{array}$ \\
\hline $\begin{array}{l}\text { H. Mizutani et } \\
\text { al., [10] }\end{array}$ & HJFET & $\begin{array}{c}\text { Distributed FET structure, } \\
\text { shunt }\end{array}$ & SPST & $\mathrm{DC} \sim 110$ & $<2.55$ & $>22.2$ & $\begin{array}{c}0.85 \mathrm{X} \\
0.45\end{array}$ \\
\hline $\begin{array}{c}\text { P. Bermkopf et } \\
\text { al., [11] }\end{array}$ & MESFET & Shunt & SPDT & $15 \sim 30$ & $2 \sim 3$ & $>20$ & $2 \times 2.2$ \\
\hline This work & HEMT & $\begin{array}{c}\text { Traveling-wave concept, } \\
\text { shunt }\end{array}$ & SPDT & $15 \sim 80$ & 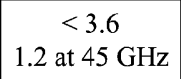 & $>25$ & $1.5 \times 1.5$ \\
\hline This work & HEMT & $\begin{array}{c}\text { Traveling-wave concept, } \\
\text { shunt }\end{array}$ & SPDT & $\mathrm{DC} \sim 60$ & $<3$ & $>25$ & $1 \mathrm{X} 1$ \\
\hline This work & HEMT & $\begin{array}{c}\text { Traveling-wave concept, } \\
\text { shunt }\end{array}$ & SPST & $\mathrm{DC} \sim 80$ & $<3$ & $>24$ & $1 \times 0.75$ \\
\hline
\end{tabular}

* Area of switch portion estimated from the entire MMIC chip (LNA + switch) [5].

perform the on-wafer measurement, the SPDT switch test circuit, which has a $50-\Omega$ termination, was also fabricated, and Fig. 17(b) shows the chip photograph. An SPST switch, which is part of the SPDT switch, was also fabricated, and Fig. 18 shows the schematic and chip photograph. The chip size of this SPST switch is $1 \mathrm{~mm} \times 0.75 \mathrm{~mm}$.

Fig. 19(a) shows the simulated and measured output return loss and isolation of the off state, while Fig. 19(b)-(c) presents the simulated and measured output return and insertion losses of the on state and on- and off-state input return losses of the SPST switch from $45 \mathrm{MHz}$ to $80 \mathrm{GHz}$. Below $80 \mathrm{GHz}$, the measured insertion loss and isolation are better than 3 and $24 \mathrm{~dB}$, respectively. From $45 \mathrm{MHz}$ to $80 \mathrm{GHz}$, the measured on-state input and output return losses are better than 10 and $8 \mathrm{~dB}$, respectively.

Fig. 20(a) shows the simulated and measured output return loss and isolation of the off state, while Fig. 20(b)-(c) presents the simulated and measured output return loss and insertion loss of the on state and on- and off-state input return losses of the SPST switch from $45 \mathrm{MHz}$ to $80 \mathrm{GHz}$. Below $80 \mathrm{GHz}$, the measured insertion loss and isolation are better than 3 and $24 \mathrm{~dB}$, respectively. From $45 \mathrm{MHz}$ to $80 \mathrm{GHz}$, the measured on-state input and output return losses are better than 10 and $8 \mathrm{~dB}$, respectively. The power performance of this SPDT switch was also measured via on-wafer probing. Fig. 21 shows the measured insertion loss and isolation versus input power. The measured insertion loss degrades $1 \mathrm{~dB}$ while the input power is $27.5 \mathrm{dBm}$. The isolation performance starts to degrade at $20-\mathrm{dBm}$ input power and becomes $13 \mathrm{~dB}$ while the input power achieves $27 \mathrm{dBm}$.

Table I lists the features and performance of the previously reported passive FET switches. Most of the reported millimeter-wave passive FET switches are narrow-band design. 
The bandwidths of these switches are comparable to the previously reported passive FET switches using a special layout/process [9], [10].

\section{CONCLUSION}

By employing the traveling-wave concept, three wide-band switches have been developed. Both of the simulated and measured results of these switches have been presented. The design procedures and circuit parameters of the SPST traveling-wave switch have also been discussed in this paper. It has been concluded that the switch using a larger device size has better isolation and poor insertion loss, while the switch with more transistors has better isolation, but does not affect the insertion loss significantly. Therefore, one can choose the proper device size to achieve the desired bandwidth of insertion loss first, and then determine the number of transistors to achieve the isolation. Regarding the implementation of the SPDT traveling-wave switch, one can used quarter-wavelength transformers to achieve a bandpass characteristic, and use additional series switches to obtain a low-pass characteristic. It is observed that the monolithic passive HEMT switches using the traveling-wave concept achieve good performance with compact chip size.

\section{ACKNOWLEDGMENT}

The chip was fabricated by the TRW foundry service through the National Chip Implementation Center (CIC) of Taiwan, Taiwan, R.O.C. The authors would like to thank G. G. Boll, GGB Industries Inc., Naples, FL, for providing the $W$-band RF probes. The authors also thank Dr. C.-H. Wang, National Taiwan University, Taipei, Taiwan, R.O.C., for his help on the chip testing.

\section{REFERENCES}

[1] E. Alekseev and D. Pavlidis, " $77 \mathrm{GHz}$ high-isolation coplanar transmitreceive switch using InGaAs/InP PIN diodes," in Gallium Arsenide Integrated Circuit Symp., 1998, pp. 177-180.

[2] G. L. Lan, D. L. Dunn, J. C. Chen, C. K. Pao, and D. C. Wang, "A high performance $V$-band monolithic FET transmit-receive switch," in IEEE Microwave and Millimeter-Wave Monolithic Circuits Symp. Dig., June 1988, pp. 99-101.

[3] H. Takasu, F. Sasaki, H. Kawasaki, H. Tokuda, and S. Kamihashi, "W-band SPST transistor switches," IEEE Microwave Guided Wave Lett., vol. 6, pp. 315-316, Sept. 1996.

[4] D. L. Ingram, K. Cha, K. Hubbard, and R. Lai, " $Q$-band high isolation GaAs HEMT switches," in IEEE GaAs Integrated Circuits Symp. Dig., Orlando, FL, Nov. 1996, pp. 282-289.

[5] D. C. W. Lo, H. Wang, B. R. Allen, G. S. Dow, K. W. Chang, M. Biedenbender, R. Lai, S. Chen, and D. Yang, "Novel monolithic multifunctional balanced switching low noise amplifiers," IEEE Trans. Microwave Theory Tech., pt. 2, vol. 42, pp. 2629-2634, Dec. 1994.

[6] K. Y. Lin, Y. J. Wang, D. C. Niu, and H. Wang, "Millimeter-wave MMIC single-pole-double-throw passive HEMT switches using impedance transformation networks," IEEE Trans. Microwave Theory Tech., vol. 51, pp. 1076-1085, Apr. 2003.

[7] M. J. Schindler and A. Morris, "DC-40 GHz and 20-40 GHz MMIC SPDT switches," IEEE Trans. Microwave Theory Tech., vol. MTT-35, pp. 1486-1493, Dec. 1987.

[8] T. Shimura, Y. Mimino, and K. Nakamura, "High isolation $V$-band SPDT switch MMIC for high power use," in IEEE MTT-S Int. Microwave Symp. Dig., vol. 1, May 2001, pp. 245-248.
[9] H. Mizutani, N. Funabashi, M. Kuzubara, and Y. Takayama, "Compact DC-60-GHz HJFET MMIC switches using ohmic electrode-sharing technology," IEEE Trans. Microwave Theory Tech., vol. 46, pp. 1597-1603, Nov. 1998.

[10] H. Mizutani and Y. Takayama, "DC-110-GHz MMIC traveling-wave switch," IEEE Trans. Microwave Theory Tech., vol. 48, pp. 840-845, May 2000.

[11] P. Bermkopf, M. Schindler, and A. Bertrand, "A high power $K / K a$-band monolithic T/R switch," in IEEE Microwave and Millimeter-Wave Monolithic Circuits Symp. Dig., June 1991, pp. 15-18.

[12] W. H. Tu, P. Y. Chen, K. Y. Lin, H. Wang, and R. B. Wu, "A $15-80 \mathrm{GHz}$ MMIC SPDT switch using traveling-wave concept," in Asia-Pacific Microwave Conf. Tech. Dig., Kyoto, Japan, Nov. 2002, pp. 57-59.

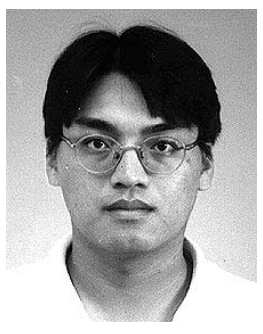

Kun-You Lin (''00-M'04) was born in Taipei, Taiwan, R.O.C., in 1975. He received the B.S. degree in communication engineering from the National Chiao Tung University, Hsinchu, Taiwan, R.O.C., in 1998, and the Ph.D. degree in communication engineering from the National Taiwan University, Taipei, Taiwan, R.O.C., in 2003.

He is currently a Post-Doctoral Research Fellow with the Graduate Institute of Communication Engineering, National Taiwan University. His research inand millimeter-wave circuits. terests include the design and analysis of microwave

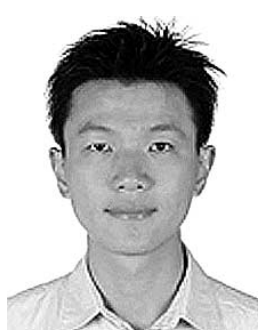

Wen-Hua Tu was born in Chiayi, Taiwan, R.O.C., in 1977. He received the B.S. degree in communication engineering from the National Chiao Tung University, Hsinchu, Taiwan, R.O.C., in 1999, the M.S. degree in communication engineering from the $\mathrm{Na}-$ tional Taiwan University, Taipei, Taiwan, R.O.C., in 2001, and is currently working toward the Ph.D. degree in electrical engineering at Texas A\&M University, College Station.

Since 2003, he has been a Research Assistant with the Electromagnetics and Microwave Laboratory, Texas A\&M University, where his research interests include wide-band antenna array design.

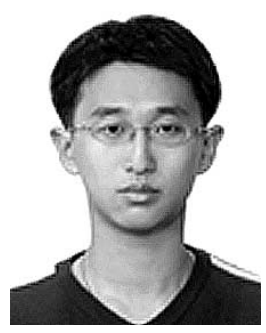

Ping-Yu Chen received the B.S. and M.S. degrees in electrical engineering from the National Taiwan University (NTU), Taipei, Taiwan, R.O.C., in 2000 and 2002, respectively.

$\mathrm{He}$ is currently serving as a Communication Officer in the Ministry of National Defense, R.O.C. His research interests include MMIC design and largeand small-signal device modeling.

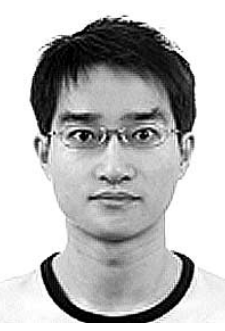

Hong-Yeh Chang ( $\mathrm{S}^{\prime} 02$ ) was born in Kinmen, Taiwan, R.O.C., in 1973. He received the B.S. and M.S. degrees in electric engineering from the National Center University, Chung-Li, Taiwan, R.O.C., in 1995 and 1997, respectively, and is currently working toward the Ph.D. degree in communication engineering at the National Taiwan University, Taipei, Taiwan, R.O.C.

In 1998, he joined Chunghwa Telecom Laboratories, Taoyuan, Taiwan, R.O.C., where he was involved in the research and development of code-division multiple-access (CDMA) cellular phone systems. From 1999 to 2000, he was with Syncomm Inc., Taoyuan, Taiwan, R.O.C., where he was involved with the personal access communications system (PACS) radio port design and testing. He is currently with the Graduate Institute of Communication Engineering, National Taiwan University. His research interests include monolithic microwave and millimeter-wave (MMW) integrated-circuit designs, transmitter and power-amplifier linearization, and vector signal characterization. 


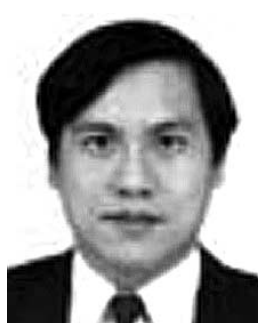

Huei Wang (S'83-M'87-SM'95) was born in Tainan, Taiwan, R.O.C., on March 9, 1958. He received the B.S. degree in electrical engineering from the National Taiwan University, Taipei, Taiwan, R.O.C., in 1980, and the M.S. and Ph.D. degrees in electrical engineering from Michigan State University, East Lansing, in 1984 and 1987, respectively.

During his graduate study, he was engaged in research on theoretical and numerical analysis of electromagnetic (EM) radiation and scattering problems. He was also involved in the development of microwave remote detecting/sensing systems. In 1987, he joined the Electronic Systems and Technology Division, TRW Inc. He was a Member of the Technical Staff and Staff Engineer responsible for MMIC modeling of computer-aided design (CAD) tools, MMIC testing evaluation, and design. He then became the Senior Section Manager of the Millimeter Wave Sensor Product Section, RF Product Center, TRW Inc. In 1993, he visited the Institute of Electronics, National Chiao-Tung University, Hsin-Chu, Taiwan, R.O.C., and taught MMIC-related topics. In 1994, he returned to TRW Inc. In February 1998, he joined the faculty of the Department of Electrical Engineering, National Taiwan University, as a Professor.

Dr. Wang is a member of Phi Kappa Phi and Tau Beta Pi.

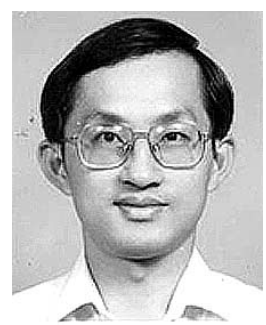

Ruey-Beei Wu (M'91-SM'97) received the B.S.E.E. and Ph.D. degrees from the National Taiwan University, Taipei, Taiwan, R.O.C., in 1979 and 1985, respectively.

He then joined the faculty of the Department of Electrical Engineering, National Taiwan University, where he is currently a Professor. He is also with the Graduate Institute of Communications Engineering, which was established in 1997. From March 1986 to February 1987, he was a Visiting Scholar with IBM, East Fishkill, NY. From August 1994 to July 1995, he was with the Electrical Engineering Department, University of California at Los Angeles. From May 1998 to April 2000, he became Director of the National Center for High-performance Computing. Since November 2002, he has also served as Director of the Planning and Evaluation Division, National Science Council. His areas of interest include computational electromagnetics, transmission-line and waveguide discontinuities, microwave and millimeter-wave planar circuits, and interconnection modeling for computer packaging. He has authored or coauthored over 50 publications appearing in IEEE publications and over 70 papers appearing in international conferences.

Dr. Wu is a member of the Phi Tau Phi Scholastic Society, the Chinese Institute of Engineers, the Chinese Institute of Electrical Engineers, and the International Union of Radio Science (URSI). 